\title{
Basic problems of biogeography
}

\author{
Aldo Zullini
}

\begin{abstract}
Darwin interpreted most of biogeographic distributions as a consequence of dispersal events. The dispersionist approach lasted till the half of the XX century, but then an alternative paradigm arose: vicariantist biogeography. Madagascan carnivores and lemurs, e.g., were considered as heirs of old Gondwanian ancestors. But new phylogeographic research, based on molecular biology, discovered that they evolved, in different times, after the parting of Madagascar from continental Africa, supporting the dispersionist approach. Nowadays, the two paradigms are welcome in all the different cases, thus avoiding the old disputes typical of the last century.
\end{abstract}

Keywords: Biogeography, vicariance, dispersal, panbiogeography, phylogeography.

Riassunto - Problemi basici in biogeografia.

Darwin interpretò le distribuzioni degli organismi quali effetti di fenomeni di dispersione. L'approccio dispersionista è durato fino alla metà del XX secolo, allorquando si affermò un paradigma alternativo: la biogeografia vicariantista. Così i lemuri e i carnivori malgasci, per esempio, furono considerati gli eredi diretti di antichi antenati gondwaniani. Pochi decenni dopo, tuttavia, l'emergere della filogeografia (basata sulla biologia molecolare) ha rivalutato l'approccio dispersionista scoprendo che questi animali originarono, in tempi diversi, ben dopo la separazione del Madagascar dall'Africa continentale. Attualmente i due paradigmi sono assunti come validi purché scelti e applicati correttamente caso per caso.

Keywords: Biogeografia, vicarianza, dispersione, panbiogeografia, filogeografia.

\section{Introduction}

It is well known that the first Europeans who have settled on the American continent had several surprises. One of them was to find a different flora and fauna, hence the problem: were these strange creatures perhaps the product of a separate creation, different from that of Eden? And, even more important: from what part of the Noah's offspring had these inhabitants come? Were a lost tribe of

\footnotetext{
Università degli Studi di Milano-Bicocca, Piazza della Scienza 2, 20126 Milano, Italia.

E-mail: aldo.zullini@unimib.it

(C) 2018 Aldo Zullini
}

Received: 19 September 2017

Accepted for publication: 13 February 2018
Israel? These questions, impossible to answer, caused a serious cultural shock. Now we know that Native Americans (at least most of them) stem from ancient Asian populations migrated from Siberia. But several biogeographic problems still remain all over the world. The iguana family, e.g., is strangely scattered in the following areas: American continent, Madagascar, and some Pacific islands (Fiji, Tonga). Probably it is a vicariance case, but how this happened is controversial. Still in 2006 Noonan and Chippindale wrote that the origin of the Malagasy fauna is one of the big mysteries of natural history. And this notwithstanding the excellent research already done in this island. Moreover, there are other similar intriguing problems: why the southern beeches (genus Nothofagus, including 43 species) exclusively surround the southern Pacific lands such as Australia, New Zealand, New Guinea and, on the opposite oceanic side, the Andean region? Similar examples of strange geographic distributions are countless and often with no single clear explanation (Humphries, 1981; Cook \& Crisp, 2005; Heads, 2006).

Other unresolved biogeographic problems concern the maximum number of species a given island (or any geographic area) can support. Not to mention the practical impossibility to predict which species can actually colonize a given area. But it is not over: we do not even know if the two million known species (animals, plants, fungi, protists, bacteria) are one half, one tenth or one hundredth of the actual species living in our planet. Moreover, there are other biogeographic problems connected with ecological processes. It is important, e.g., to assess the localization and extension of the present and former forests, and the factors affecting their development and decline. It is a commonplace (even if improper) to affirm that the tropical forests, and the Amazon one in particular, are the green lungs of the world. But the biogeography of the past seems to prove that such forests did not exist for most of the Earth's history. Yet the amount of atmospheric oxygen has always remained relatively constant: are perhaps forests not so crucial in this respect? (Stott, 1999). Biogeography is the science that explains why organisms are distributed the way we see today (Platnick \& Nelson, 1978) and therefore it is intended to interpret the spatial patterns of biodiversity (Brown \& Lomolino, 1998). In other words, the fact that giraffes live in Africa and not in Europe is 
due to a number of essentially ecological factors (climate, vegetation type, etc.), while the fact that they live in Africa but not in South America is due to complex geological and evolutionary events: this is a typical biogeographic problem (Zunino \& Zullini, 2004).

\section{Vicariance or dispersal?}

Among the founders of biogeography we would like to mention Alexander von Humboldt (1769-1859), a tireless explorer of South America and Siberia, countries where he collected and studied tens of thousands of plants and landscapes, and Alfred Russel Wallace (1823-1913) zoologist, co-founder of Darwinism and another tireless scholar and explorer of the Amazon and Southeast Asia. Both died at age 90 and were scientifically very active until their last days. Wallace had strong biogeographical interests and is famous for giving definite shape to the world's zoogeographic division into 5 regions: Palearctic (Eurasia), Nearctic (North America), Ethiopia (or Paleotropic), Oriental (India and Southeast Asia), and Australasia. Also, influenced by Darwin, he concluded that the geographical distribution of animals had always been an effect of dispersal phenomena. Thus began the development of dispersalist biogeography that saw in mass migrations, or in the accidental movement of individuals, the cause of disjointed distributions. A disjoint distribution is a not continuous distribution area (range), usually placed before and beyond a barrier. A barrier is an obstacle preventing, more or less effectively, the spread of a species from one area to another. It can be a mountain chain, a sea arm, a river, a desert, or a climatic factor, or other obstacle. Once a barrier is broken down, individuals of a certain species can form a new population virtually identical to the old one, and as a result the species itself will display a disjointed area, occupying two separate territories. From this point onwards the two populations, now practically isolated from each other, can evolve on their own in different ways and, after many generations, assume different characters. In the long run they can become two distinct species, formed by individuals no longer interconnected with each other (speciation by allopatry). Species (closely related) found here and beyond a barrier are called vicariant (= corresponding) species. This biogeographic-evolutionary mechanism is the basis for many geographical distributions of plants and animals. The dispersalist interpretation of the biogeographic patterns (which interprets the distribution area as derived from a source center of a species which then disperses elsewhere) continued unchallenged until the mid-twentieth century. This theory considered the lands as a fixed scenario over which the organisms moved and evolved.

In 1912 Alfred Wegener proposed the theory of continental drift, but it was not taken seriously due to insufficient evidence. Only in biology, starting with René Jeannel (1879-1965), biogeographic arguments were developed to support the new mobilistic theory. Only after half a century, in the 1960s, geologists found evidence of the mobility of large parts of the earth's crust, called tectonic plates, which involved, over millions of years, continuous separations and mergers of large stretches of emerging lands. The mobile scenario, already hypothesized by some bioge- ographers (e.g. Wallace first way, and L. Croizat), finally gave the rationale for a plausible explanation of species, genera and families distributions. Many animal and plants, e.g., are typical of the southern continents (South America, Africa, Australia), now separated by huge oceanic expanses. These same continents, however, used to be joined together (and with Antarctica) about 180 million years ago to form a supercontinent called Gondwana. This supercontinent was inhabited by a set of organisms that only later became separate into the mentioned continents, but whose descendants show evident affinities. According to many authors, among the "southern" organisms of gondwanian origin there is a family of non-flying birds (ostriches, cassowaries, emu, kiwi), the aforementioned southern beech trees, as well as various groups of insects, plants and other organisms. This allowed a change of perspective: organisms live essentially embedded in their territory while their displacements in space are limited: they are passively bound to their area. It is rather the earth's crust that, together with the organisms that populate it, crumbles and moves by determining the pattern of current distributions: earth and organisms evolve together (Croizat, 1962). The living community that covers the surface of the planet is thus treated as a sort of geological layer whose vicissitudes are consistent with those of the underlying rocks. The ancient species, far from barrier jumping and far from unlikely distance dispersals, had their ground breaking thus creating over time new (vicarious) species. This kind of interpretation is known as vicariance biogeography. It follows that the barriers are formed after the formation area of a species, while barriers do not exist before as stated by dispersalist biogeography. A common vicariance assumption is that there is no need to assume any long-distance migration to or from anywhere - the groups have simply evolved where they are and their distribution will be found to be of Mesozoic age.

The vicariance approach has remarkable correspondences with a modern way of considering the evolutionary tree: the phylogenetic systematics, commonly called cladistics by the entomologist Willi Hennig that emerged in the 1960s. Often the vicariance biogeographical analysis and those of systematic cladistics are mutually supportive. Such systematics privileges true relationships of kinship (recognizing only exclusive groups called monophyla) rather than groups based of phenotypic similarity. Thus, for example, the concept of "Reptiles" is rejected because crocodiles (reptiles), though similar to lizards (reptiles), are however genetically more closely related with birds. Therefore, reptiles are an artificial, unnatural category, since it is not a monophyletic grouping (but paraphyletic, that is incomplete, since monophylum is a set consisting of an ancestral species and all its descendants). Vicariance biogeography aims not only at studying species and species groups, but also reconstruct geographic events (fragmentation and mergers) of geographic areas by studying the distribution of existing species. Everyone knows that the task of the systematic biologist is to reconstruct relationships between species, that is deducing the evolutionary tree (using tree-branched diagrams or cladograms) after analysing the presence/absence of certain somatic characters. Likewise, the task of the vicariance 
biogeographer is the reconstruction of area relationships (sister areas) by area cladograms based on the presence/ absence of certain species (Humphries \& Parenti, 1986). The underlying cladistic biogeography is that general patterns require general explanations. An extreme vicariance thinking line is Panbiogeography, so called by León Croizat (1894-1982) because it is based on parallel evolution and interaction between geography and biology ("flesh and rocks evolve together"). Its fundamental tenet is expressed by the triadic concept of space-time-form (thus time and space become part of the very concept of species); this implies the rejection of the classic concept of center of origin and dispersal, typical of dispersalism. The focal point is not the spatial interpretation of a species or groups of species, but the evolution of the entire biotas studied by the lines (tracks) connecting all the localities occupied by the studied species. Unlike the traditional Wallaceian biogeographic regionalization based on continental masses (see above), panbiogeography identifies the pivot of terrestrial organisms in the ocean basins. In this perspective, for example, southern beeches insist on a base of the $\mathrm{Pa}$ cific Ocean, while ostriches (and the like) insist on a baseline of the Atlantic and Indian oceans (Craw et al. 1999). Panbiogeography is controversial being considered not a useful approach for evolutionary biology [for example, see Waters et al. (2013), but also see the reply in Heads (2014a)] and also because it is founded, particularly at its start, on evolutionary assumptions of orthogenetic type. This means to assume internal tendencies of populations to vary in certain predetermined directions (polyphyly) irrespective of environmental variation and random mutations. This implies a polytopic origin for many taxa, i.e. a simultaneous evolution of many parallel lines in several (also very distant from each other) species and genera to overcome the problem of large-scale migrations. But serious objections are: by what mechanism do tectonic zones of disturbance influence the development of species? And what kind of evidence would falsify the panbiogeographic assumption of vicariance? (McGlone, 2015).

Cladistic biogeography rests upon the assumption that if there is congruence between phylogenetic and biogeographic patterns, then they probably share a common history. In order to have significant data, monophyletic taxa only must be considered. Moreover, widespread taxa, redundant distributions and missing areas must be correctly weighted and minimized to avoid inconsistencies or ambiguities. After building phylogenetic taxa cladograms, area cladograms are obtained replacing the terminal taxa with their distribution areas. Afterwards a quantitative method was proposed (Ronquist, 1997), the Dispersal-Vicariance Analysis (DIVA), to assess the respective impact of these two models relying on the criterion of parsimony. His method minimizes dispersal and extinction events (both rated at "cost" 1) whereas speciation due to vicariance is rated at "cost" 0 . The most probable outcome (historical reconstruction) is assumed to be the one with the lowest cost. DIVA criticism underlines the fact that it reconstructs histories accurately when evolution has been simple, where speciation is driven mainly by vicariance. But ancestral areas are wrongly identified in complex patterns of dispersals and within-area speciation events (Kodandaramaiah,
2009). Many improvements and alternative methods have been proposed since then (for example, see Yan et al., 2015). Serious critics to cladistic biogeographic methods points out the lack of incorporation of the absolute timing of taxa diversification in the component lineages, leading to mix clades of different ages into a fictitious single vicariant event. Moreover, such methods overlook the possibility of directional (asymmetric) long-distance dispersal. These difficulties can only be solved applying methods integrating fossil and molecular data (Donogue, 2003).

From the above, the importance of vicariance research, tectonics and systematic cladistics, since 1960 is evident. Dispersal events were judged of secondary or even negligible importance and the dispersalism was dubbed as a science of the improbable. On the contrary, in recent years, especially after 2000 , emerged a third big turning point, as a consequence of molecular analysis in biogeography. A new chapter in science come to light: Phylogeography i.e. the study of geographic relationships of very close evolutionary lines (phyletics), even within the same species. In other words, it analyses the spatial effects of microevolutionary processes, that is the recent evolution of similar species or populations within a same species. This is made possible by the DNA amplification and sequencing techniques allowing even the subtlest genetic differences between individuals, populations, or species to be compared. Molecular data also allows us to date (e.g. with the relaxed-clock system) the moments of formation of species or populations. The data emerging in recent years demonstrate that dispersal phenomena, even at great distances, are much more numerous, and also recent, than generally believed by vicariance biogeography. In Madagascar, for example, it has been seen that many animal groups, such as lemurs and carnivores, already considered the heirs of ancient Gondwanian lineages (when this island was united to Africa), are actually the result of a recent evolution occurred after Madagascar's detachment from the continent. In fact, Malagasy species (including fossil) of both groups form two monophyletic groups, both of which derive from a single founding species of the respective group, species of African origin. If, in fact, Malagasy lemurs and carnivores stemmed their existence from a single biogeographic event (vicariant or, according to other authors, a temporary land bridge) then the two respective ancestors should be about the same age. But molecular analysis (Yoder et al., 2003) show that the ancestor of all Malagasy lemurs lived about 65 million years ago, while the ancestor of the Malagasy carnivores lived about 20 million years ago. This is difficult to explain in a vicariance view, while suggesting the existence of separate dispersals. Some land mammals, belonging to different orders, are able to cope with long periods of hibernation or drowsiness during which they may be transported by ocean currents (Kappeler, 2001). There is also an ice bridge hypothesis according to which circa $27 \mathrm{Myr}$ ago the sea level lowered reducing the distance from mainland Africa to Madagascar (Zhou et al. 2017).

Some acrobat ants (genus Crematogaster with almost 500 species) moved from Africa to Madagascar during Miocene when eastwards oceanic currents were still 
operating (then they reversed to the nowadays opposite configuration). Now Madagascar hosts 32 Crematogaster species (all endemic) and the interesting aspect is that molecular data show that they stem not from one or two, but from eight dispersal events from Africa. This can be explained with the arboreal nesting habits of this genus and subsequent rafting with floating plant material (Blaimer, 2012). It is true that phylogenetic data also show Asian affinities with Madagascar, but often this is an effect of a high frequency of dispersal rather than of an ancient vicariant origin (Warren et al., 2010). Also the biogeography of palms (Arecaceae) appears to be the result of long-distance dispersal events (Baker \& Couvreur, 2013). Frogs do not tolerate the osmotic stress of salt water and their larvae need freshwater habitats, therefore they are originally absent in oceanic islands (islands emerged from sea bottom, never in contact with a continent, e.g. Hawaii, Saint Helena, Maldives). This notwithstanding, two endemic mantellid frog species were found in the volcanic island of Mayotte, $300 \mathrm{~km}$ west of Madagascar. These two species (genera Mantidactylus and Boophys), not being closely related, imply two separate overwater dispersal events from Madagascar, since no vicariant events can be assumed because the great depth $(>3400 \mathrm{~m})$ of the surrounding ocean and because their phylogenetic timing (Vences et al., 2003).

In general, most Malagasy clades show a Cenozoic origin (i.e. after $66 \mathrm{Mya}$ ), and since Madagascar separated from Africa 160 Mya and from India $88 \mathrm{Mya}$, it is evident that its present-day biota originates from (mostly African) dispersers (Yoder \& Novak, 2006). The possibility of dispersal across an ocean is also demonstrated by the populations of the most "isolated" islands in the world, the Hawaii: many molecular data relate to more or less recent colonization phenomena across the Pacific. Some contemporary authors, opposing to vicariant theories, argue that even the colonization of South America by monkeys has nothing to do with a hypothetical primitive presence of proto-monkeys in a common area (part of Gondwana) subsequently divided forming Africa and South America, well before 100 million years ago. According to new molecular data, in fact, South America would have "received" the monkeys (Platyrrhini) much more recently, around 40 million years ago, when the Atlantic Ocean had already formed. Probably, they came from Africa at a time when, due to climate change, the sea level lowered revealing some of the mid-ocean ridges (currently submerged) of the Central and Southern Atlantic (Schrago \& Russo, 2003). Different oceanic dispersal scenarios were also examined (Houle, 1999). But Heads (2014b), a steadfast critic of dispersalism, ask: "Why are haplorhine primates in America but not Madagascar, while members of the sister group, strepsirrhines, are in Madagascar but not America? Why have no primates at all crossed Salue Timpaus Strait (20 $\mathrm{km}$ across) from Sulawesi to Australasia (although monkeys introduced in New Guinea have thrived)?".

Another unexpected finding was that baobab trees (Adansonia) living in Madagascar (6 native species), Africa (2 species) and Australia (1 species) show a divergence age of less than 23 Mya, whereas the tectonic separation of these two continents occurred about 120
Mya. This means that in this case no old vicariance occurred, but a much more recent dispersal trough the Indian Ocean (Baum et al., 1998). According to some authors (Pole, 2001), even the New Zealand flora derives from transoceanic immigration and also the distribution of many Australian plants, e.g. Goodeniaceae, does not depend on vicariance (Jabaily et al., 2014). All of these contrast with the classic view stating that oceanic islands biota are essentially different from continental islands biota, the first being dispersal dependent, the latter being vicariance dependent. But why do continental islands (e.g. Madagascar, Borneo, New Zealand, Great Britain, Sicily) seem to host a very limited contingent of ancient taxa and so many recent immigrant taxa? Because the various mass extinctions, the land submergences during the Oligocene, and the cooling during the late Miocene, probably destroyed most of the biota of these territories. The biota of New Zealand and New Caledonia, e.g., resemble that of "oceanic" islands because their young immigrant organisms, rather than "continental" islands with relictual "Gondwanian" biota (Crisp et al., 2011). Also the continents, of course, were affected by submergences, but they are larger and much less fragile (from the biota point of view) than the islands.

Another objection to the vicariance paradigm concerns the alleged close correspondence between land and biota. Such correspondence, e.g., does not exist if we follow the (disputed) thesis that the Falkland Islands are, geologically, a piece of South Africa moved to South America. Knowing that these islands host typical Patagonian organisms, one could ask: what is the meaning of "area relations" (vicariance concept) between these islands and Patagonia? And what about the claim, dear to pan-biographers, that earth and life evolve together? (McDowall, 2004). Vicariance biogeographers have always argued that a vicariance-based explanation (for example, the formation of two different sets of species (biota) after the fragmentation of a common original area) is both scientific and parsimonious. Scientific, because it is possible to refute it after new studies and additional data. Parsimonious, because it can explain the concomitant formation of two sets of species (of two biota) from a single event (fragmentation of an area). In fact, explaining the origin of two different biota (in two separate areas) by means of dispersal phenomena, on the other hand, is neither scientific nor parsimonious. It is not scientific, because dispersal is an accidental and not falsifiable fact, thus escaping the scientific horizon. It is not parsimonious, because numerous dispersal events need to be postulated (at least one for each species of the new biota forming beyond a barrier). Even worse, species have very different dispersal capacities (for example: coconuts disperse with sea currents, spores of ferns by wind, not to mention the different dispersal abilities of insects, snails and frogs). For each of these events, and for each species, an ad hoc hypothesis should be formulated. The dispersalist biogeographic response is that if vicariance hypotheses are falsified (refuted), then dispersal hypotheses are automatically confirmed by default. Moreover, after the introduction of the molecular techniques mentioned above, it is no longer true that the dispersal phenomena are not scientifically testa- 
ble. According to de Queiroz (2005): “A high frequency of dispersal also suggests that a fundamental methodological assumption of many biogeographical studies - that vicariance is a priori a more probable explanation than dispersal - needs to be re-evaluated and perhaps discarded". And he concludes: "If vicariance biogeography was a revolution, we are now in the midst of a counterrevolution". McGlone's (2005) dispersalist view is even more radical when he writes: "Goodbye Gondwana".

But all the aforementioned arguments and objections against vicariance and panbiogeographic points of view are strongly rejected by some biogeographers and geneticists (Graur \& Martin, 2004) who focus on the flaws of the nodes calibration of molecular clock. Such calibrations (e.g. the "mythical" $310 \pm 0$ Mya chicken-human node calibration) give only an illusory precision. They conclude that the plethora of papers based on false and tautological calibrations are the molecular equivalents of Archbishops Ussher's date of the first day of creation (23 October 4004 $\mathrm{BC})$. The non-reliability of the molecular clock entails important consequences in biogeography laying in favour of ancient speciation events linked to vicariances. After claiming that a global molecular clock does not exist, Heads states that it is necessary to distinguish between age of being and age of fossilization: "Other plants and animals regularly invade younger exposed strata which appear in their vicinity, with the older land surfaces subsequently disappearing (...) A particular cliff, valley or volcano may be recent, but this does not mean that the habitat type is recent". After dubbing modern phylogeography as a "house of cards", he dismiss the dispersal biogeography stating: "We only know that long-distance dispersal is frequent because the dates of many nodes (...) are recent, and we only know they are recent because they were calibrated with fossils". And the oldest known fossil, of course, does not coincide with the origin of its taxon (Heads, 2005). But according to de Queiroz: "Heads' view that the fossil record provides no information about the maximum ages of groups is extraordinary and, for an evolutionist, truly mystifying. His arguments imply that we should not be surprised at the discovery of Cretaceous humans, or of Precambrian lagomorphs, especially if their distributions could be explained by vicariance!"' (de Queiroz, 2016).

In fact, we must consider that molecular clocks methods improved a lot since the 2005 Head's paper, so much of the traditional criticism of cladistics approaches to palaeontology is now overcome (for example, see Donogue \& Yang, 2016). And some authors (Waters, 2008) insist on the dispersal paradigm stating that parts of Gondwana (e.g. Chatham Islands) were drowned during Oligocene, so their terrestrial and littoral biotas were completely lost; therefore the panbiogeographic scenarios involving vicariant origins of existing lineages must be false. The case of the southern kelps of the genus Durvillaea is also interesting in this regard. Species of this genus are solid-bladed (therefore non-buoyant) living in very restricted areas (southern New Zealand, southern Australia, Tasmania, Chatham Islands, Antipodes Islands); only one species, Durvillaea antarctica, is honeycomb-bladed and buoyant. It was estimated that there are at any one time 70 million rafts of this kelp in the Southern Ocean. As a consequence of such kind of dispersal, this alga inhabits New Zealand, Chile, Falkland Islands, Kerguelen, and other ten island groups all around the globe between 40 and 60 degrees latitude. This fact, by the way, contradicts the panbiogeographic tenet that the distribution pattern does not depend on the dispersal abilities of the organisms. It is important to note that $D$. antarctica hosts benthic invertebrates and can transport them by rafting at long distances. Starfish Parvulastra exigua (devoid of pelagic larval phase) inhabits South Africa, Amsterdam Island, southern Australia, Tasmania and Lord Hove Island. Given that these populations exhibit very closely related mtDNA haplotypes, this pattern is probably a consequence of kelp rafting driven by the West Wind Drift and Antarctic Circumpolar Current, corroborating a dispersalist view (Waters, 2008). Other authors (Sanmartín \& Ronquist, 2004; Sanmartín et al., 2007) after a detailed analysis, found that in the southern hemisphere animal data are congruent with the geological sequence of Gondwana breakup, whereas plant distribution patterns (e.g. that Australia being related with New Zealand, unlike the results emerging from animal data) are better explained by dispersal. But vicariantists (Heads, 2005) object that such analysis is invalid because the territories taken in consideration (New Zealand, Australia, New Guinea, New Caledonia) as terminal cladogram areas are all biogeographically and geologically composite being the result of terrane amalgamation after the Gondwana breakup. Moreover, distribution analysis of the southern genus Abrotanella (Asteraceae, cushion plants) would show that allopatry is caused by vicariance and that overlap is caused by dispersal (Heads, 2012).

One solution to solve the dilemma is to observe that the two paradigms (vicariance and dispersalism) are not mutually exclusive and cannot be considered a priori one better than the other, because each of them can explain, depending on the cases, a certain geographic distribution in a satisfactory way (McDowall, 2004; Costa Wilson, 2010; Cai et al., 2014). McGlone (2015), e.g., while supporting dispersalism, affirms: "I accept that for some distributions, in particular many of those involving freshwater fish and terrestrial mammals, vicariant explanations are highly plausible". The classical vicariant model can be integrated with a dynamic vicariance model focusing on the shift of distribution areas, and not necessarily on the respective physical areas. This is the case of a climate change moving the area of a given biota along the latitudinal direction: such a biota, during its displacement, can encounter a barrier, such as a North-South elongated sea, parting its sides; as a result, the biota settles on the opposite shores of that sea. In conclusion, to obtain a good biogeographic interpretation it is perhaps convenient to start with a vicariance approach, because it is more general and easier to control. But if it does not work, then alternative hypotheses based on dispersal, supported by molecular data, are to be made (Zunino \& Zullini, 2004; Waters \& Craw, 2006). Since things always are more complicated than expected, it seems appropriate to conclude noting that "the geographical evolution of biota has been driven by a greater diversity of processes with a more complex history than under a simple vicariance (or dispersal) paradigm" (Crisp \& Trewick, 2011). 


\section{References}

Baker W. J. \& Couvreur T. L. P., 2013 - Global biogeography and diversification of palms sheds light on the evolution of tropical lineages. I. Historical biogeography. Journal of Biogeography, 40: 274-285.

Baum D. A., Small R. L. \& Wendel J. F., 1998 - Biogeography and floral evolution of baobabs (Adansonia, Bombacaceae) as inferred from multiple data sets. Systematic Biology, 47: 181-207.

Blaimer B. B., 2012 - Acrobat ants go global - Origin, evolution and systematics of the genus Crematogaster (Hymenoptera: Formicidae). Molecular Phylogenetics and Evolution, 65: 421-436.

Brown J. H. \& Lomolino M. V., 1998 - Biogeography. Sinauer Assoc. Inc., Sunderland, Mass.

Cai Q., Tulloss R. E., Tang L. P., Tolgor B., Zhang P., Chen Z. H. \& Yang Z. L., 2014 - Multi-locus phylogeny of lethal amanitas: implications for species diversity and historical biogeography. $B M C$ Evolutionary Biology, 14: 143-158.

Cook L. G. \& Crisp M. L., 2005 - Not so ancient: the extant crown group of Nothofagus represents a post-Gondwanan radiation. Proceedings of Biological Sciences, 272: 2535-2544.

Costa Wilson J. E. M., 2010 - Historical biogeography of cynolebiasine annual killifishes inferred from dispersal-vicariance analysis. Journal of Biogeography, 39: 1995-2004.

Craw R. C., Grehan J. R. \& Heads M. J., 1999 - Panbiogeography. Tracking the history of life. Oxford Biogeography series, Oxford,11.

Crisp M. D., Trewick S. A. \& Cook L. G., 2011 - Hypothesis testing in biogeography. Trends in Ecology and Evolution, 26: 66-72.

Croizat L., 1962 - Space, Time, Form: the biological synthesis. $\mathrm{Ca}$ racas.

de Queiroz A., 2005 - The resurrection of oceanic dispersal in historical biogeography. Trends in Ecology and Evolution. 20: 68-73.

de Queiroz A., 2016 - Jurassic primates, immobile ducks and other oddities: a reply to Head's review of The Monkey's Voyage. Australian Systematic Botany, 29: 403-423.

Donogue M. J. \& Moore B. R., 2003 - Toward an integrative historical biogeography. Integrative and Comparative Biology, 43: 261-270.

Donogue P. C. J. \& Ziheng Y., 2016 - The evolution of methods for establishing evolutionary timescales. Philosophical Transactions of the Royal Society, B 371: 20160020.

Graur D. \& Martin W., 2004 - Reading the entrails of chickens: molecular timescales of evolution and the illusion of precision. TRENDS in Genetics, 20: 80-86.

Heads M., 2005 - Dating nodes on molecular phylogenies: a critique of molecular biogeography. Cladistics, 21 (2005): 62-78.

Heads M., 2006 - Panbiogeography of Nothofagus (Nothofagacecae): analysis of the main species massings. Journal of Biogeography, 33: 1066-1075.

Heads M., 2012 - South Pacific biogeography, tectonic calibration, and pre-drift tectonics: cladogenesis in Abrotanella (Asteraceae). Biological Journal of the Linnean Society. Linnean Society of London, 107: 938-952.

Heads M., 2014a - Panbiogeography, its critics, and the case of ratite birds. Australian Systematic Botany, 27: 241-256.

Heads M., 2014b - Biogeography by revelation: investigating a world shaped by miracles. Australian Systematic Botany, 27: 282-304.

Houle A., 1999 - The origin of Platyrrhines: an evaluation of the Antarctic scenario and the floating island model. American Journal of Physical Anthropology, 109: 541-559.

Humphries C. J., 1981 - Biogeographical methods and the southern beeches (Fagaceae: Nothofagus) In: Advances in cladistics. Funk V. A. \& Brooks D. R. (eds). The New York Botanical Garden, New York: $177-207$.

Humphries C. J. \& Parenti L. R., 1986 - Cladistic Biogeography: Interpreting Patterns of Plant and Animal Distributions. Oxford University Press, Oxford.

Jabaily R. S., Shepherd K. A., Gardner A. G., Gustafsson M. H. G., Howarth D. G. \& Motley T. J., 2014 - Historical biogeography of the predominantly Australian plant family Goodeniaceae. Journal of Biogeography, 41: 2057-2067.

Kappeler P. M., 2001 - Lemur origins: rafting by groups of hibernators? Folia Primatologica, 71: 422-425.
Kodandaramaiah U., 2009 - Use of dispersal-vicariance analysis in biogeography - a critique. Journal of Biogeography, Wiley Online Library. < doi.org/10.1111/j.1365-2699.2009.02221.x>

McDowall R. M., 2004 - What biogeography is: a place for process. Journal of Biogeography, 31: 345-351.

McGlone M. S., 2005 - Goodbye Gondwana. Journal of Biogeography, 32: 739-740.

McGlone M. S., 2015 - Once more into the wilderness of panbiogeography: a reply to Heads (2014). Australian Systematic Botany, 28: 388-393.

Noonan B. P. \& Chippindale P. T., 2006 - Vicariant origin of Malagasy reptiles supports late Cretaceous antarctic land bridge. The American Naturalist, 168: 730-741.

Platnick N. I. \& Nelson G., 1978 - A method of analysis for historical biogeography. Systematic Zoology, 27 (1): 1-16.

Pole M. S., 2001 - Can long-distance dispersal be inferred from the New Zealand plant fossil record? Australian Journal of Botany, 49 (3): $357-366$

Ronquist F., 1997 - Dispersal-vicariance analysis: a new approach to the quantification of historical biogeography. Systematic Biology, 46: 195-203.

Sanmartín I. \& Ronquist F., 2004 - Southern hemisphere biogeography inferred by event-based models: plant versus animal patterns. Systematic Biology, 53: 216-243.

Sanmartín I., Wanntorp L. \& Winkworth C., 2007 - West Wind Drift revisited: testing for directional dispersal in the Southern Hemisphere using event-based tree fitting. Journal of Biogeography, 34: 398-416.

Schrago C. G. \& Russo C. A. M., 2003 - Timing the origin of New World monkeys. Molecular Biology and Evolution, 20: 16201625.

Stott Ph., 1999 - Tropical rain forest: a political ecology of hegemonic myth making. IEA Environment Unity, London.

Vences M., Vieites D. R., Glaw F., Brinkmann H., Kosuch J., Veith M. \& Meyer A., 2003 - Multiple overseas dispersal in amphibians. Proceedings of the Royal Society, London, Ser. B 270: 24352442.

Warren B. H., Strasberg D., Bruggermann J. H., Prys-Jones R. P. \& Thébaud C., 2010 - Why does the biota of the Madagascar region have such a strong Asiatic flavour? Cladistics, 26: 526-538.

Waters J. M., 2008 - Driven by the West Wind Drift? A synthesis of southern temperate marine biogeography, with new directions for dispersalism. Journal of Biogeography, 35: 417-427.

Waters J. M. \& Craw D., 2006 - Goodby Gondwana? New Zealand biogeography, geology, and the problem of circularity. Systematic Biology, 55: 351-356.

Waters J. M., Trewick S. A., Paterson A. M., Spencer H. G., Kennedy M., Craw D., Burridge C. P. \& Wallis G. P., 2013 - Biogeography off the tracks. Systematic Biologist, 62: 494-498.

Yan Y., Harris A. J., Blair C. \& He X., 2015 - RASP (Reconstruct Ancestral State in Phylogenies): A tool for historical biogeography. Molecular Phylogenetics and Evolution, 87: 46-49.

Yoder A. D., Burns M. M., Zehr S., Delefosse T., Veron G., Goodman S. M. \& Flynn J. J., 2003 - Single origin of Malagasy carnivora from an African ancestor. Nature, 421: 734-737.

Yoder A. D. \& Nowak W. D., 2006 - Has vicariance or dispersal been the predominant biogeographic force in Madagascar? Only time will tell. Annual Review of Ecology, Evolution, and Systematics, 37: 405-431.

Zhou Y., Wang S. R. \& Ma J. Z., 2017 - Comprehensive species set revealing the phylogeny and biogeography of Feliformia (Mammalia, Carnivora) based on mitochondrial DNA. PLoS One, 12: e0174902.

Zunino M. \& Zullini A., 2004 - Biogeografia. La dimensione spaziale dell'evoluzione. Casa Editrice Ambrosiana, Milano. 